\title{
Chicory Roots for Prebiotics and Appetite Regulation: A Pilot Study in Mice
}

\author{
Marion Fouré, ${ }^{\dagger}$ Camille Dugardin, ${ }^{\dagger}$ Benoît Foligné, ${ }^{\ddagger}$ Philippe Hance, ${ }^{\dagger}$ Thierry Cadalen $^{\dagger}$ \\ Abigael Delcourt, ${ }^{\dagger}$ Bernard Taminiau, ${ }^{\S}$ Georges Daube, ${ }^{\S}$ Rozenn Ravallec, ${ }^{\dagger}$ Benoit Cudennec, ${ }^{\dagger}$ \\ Jean-Louis Hilbert, ${ }^{\dagger}$ and Anca Lucau-Danila* ${ }^{\dagger} \dagger$ \\ †EA 7394, ICV-Institut Charles Viollette, Université Lille, INRA, ISA, Université Artois, Université Littoral Côte d’Opale, F-59000 \\ Lille, France \\ ${ }^{\ddagger}$ INSERM, CHRU, Université Lille, LIRIC-UMR 995, F-59000 Lille, France \\ ${ }^{\S}$ Faculty of Veterinary Medicine, FARAH, University of Liège, B-4000 Liège, Belgium
}

Supporting Information

ABSTRACT: The objectives of this work are to address the prebiotic effects of chicory (Cichorium intybus) together with its possible role in appetite control. We compared nine chicory genotypes in order to determine if variations in the content of metabolites in the roasted roots would lead to modifications in release of satiety hormones and in composition of gut microbiota. To this aim, a 5-week dietary-intervention study was achieved using mice fed with distinct chicory-based preparations. A $16 \mathrm{~S}$ rRNA gene-based metagenetic analysis of fecal microbiota was performed. In vitro gastrointestinal digestions were performed in order to study the effect of chicory intestinal digests on gut hormone regulation in enteroendocrine cells. Firmicutes/ Bacteroidetes ratio and gut bacterial groups, such as Alloprevotella, Blautia, Alistipes, and Oscillibacter, were found to be modulated by chicory. On the other hand, CCK and GLP-1 satiety hormones were demonstrated to be significantly increased by chicory in vitro.

KEYWORDS: Cichorium intybus, prebiotics, metabolomics, metagenetics, satiety hormones

\section{INTRODUCTION}

The chicory root represents the main industrial source of inulin $^{1}$ and is also used as a food ingredient in the form of flour or roasted products. It goes into our food under various forms entailing an implicit consumption of inulin. Inulin-type prebiotics include fructooligosaccharides (FOS), oligofructose, and inulin. ${ }^{2}$ They escape digestion in the digestive superior tract and arrive in the colon, where they constitute the ideal fermentative substrate for resident bacteria. These ingredients are legally classified as food or food ingredients and are included in the daily diet. ${ }^{3}$ Inulin is especially consumed and has received a notice from the European Food Safety Authority concerning positive health effects. Inulin is incorporated into numerous foodstuffs such as yogurts and cheeses, ${ }^{4}$ cakes, ${ }^{5}$ and dough. ${ }^{6}$ Added to coffee, inulin showed an effect on satiety by mitigation of the sensation of hunger. ${ }^{7}$ By reinforcing the gut microbiota, inulin participates in the increase of resistance to infections as observed for the anti-inflammatory effects on asthmatic patients. ${ }^{8}$ Similarly, by stimulating the growth of lactobacilli, inulin is able to activate T cells and NK cells as well as the phagocytes. ${ }^{9}$ Functional food refers to food containing ingredients that aid specific bodily functions in addition to being nutritious, ${ }^{10}$ and so inulin is currently used as functional food, particularly in a variety of dairy products, to enhance the intensification of the beneficial intestinal bacteria. ${ }^{11}$

A prebiotic is defined as a substrate that is selectively utilized by host microorganisms conferring to this host a health benefit. $^{12}$ This new definition expands the concept of prebiotics to include noncarbohydrate substances, applications to body sites other than the gastrointestinal tract, and diverse categories other than food. The community of microorganisms that makes up the gut microbiota has been the object of many studies. The analysis of genetic material recovered directly from environmental samples by metagenomic approaches reproduces the profile of microbial biodiversity in the initial sample. Sequence analysis of the 16S rRNA gene has been widely used to identify bacterial species from the digestive tract, and next-generation sequencing techniques that have emerged during the past decade have facilitated the rapid analysis of these samples. ${ }^{13}$ This technique facilitates the monitoring of different modifications of the gut microbiota under different treatments or diets.

Concerning the food-intake regulation, it is known that the short-term regulation implicates multiple actors including the brain and the intestine, which coordinate with nervous and endocrine signals. Intestinal hormones, secreted by enteroendocrine cells (EECs) scattered along the gastrointestinal tract, are primordial signals implicated in this regulation. Thus, in response to nutrient sensing at their apical side, EECs secrete a wide range of gut hormones acting as peripheral signals transmitted to the brain to regulate appetite, energy expenditure, and insulin secretion. ${ }^{14,15}$ Among the many hormones produced by the gut, cholecystokinin (CCK) and

Received: February 27, 2018

Revised: June 5, 2018

Accepted: June 6, 2018

Published: June 6, 2018 
Table 1. Chemical Composition, Protease Concentration, and pH Used for the Different Steps of the In Vitro Simulated Gastrointestinal Digestion

\begin{tabular}{|c|c|c|c|c|}
\hline & saliva & gastric juice & duodenal juice & bile juice \\
\hline \multirow[t]{7}{*}{ chemical composition } & $\mathrm{KCl}(12 \mathrm{mM})$ & $\mathrm{KCl}(11 \mathrm{mM})$ & $\mathrm{KCl}(7.6 \mathrm{mM})$ & $\mathrm{KCl}(5 \mathrm{mM})$ \\
\hline & $\mathrm{KSCN}(2 \mathrm{mM})$ & $\mathrm{NaH}_{2} \mathrm{PO}_{4}(2.2 \mathrm{mM})$ & $\mathrm{KH}_{2} \mathrm{PO}_{4}(0.6 \mathrm{mM})$ & $\mathrm{NaCl}(90 \mathrm{mM})$ \\
\hline & $\mathrm{NaH}_{2} \mathrm{PO}_{4}(7.4 \mathrm{mM})$ & $\mathrm{NH}_{4} \mathrm{Cl}(5.7 \mathrm{mM})$ & $\mathrm{NaCl}(120 \mathrm{mM})$ & $\mathrm{NaHCO}_{3}(69 \mathrm{mM})$ \\
\hline & $\mathrm{Na}_{2} \mathrm{SO} 4(4 \mathrm{mM})$ & $\mathrm{NaCl}(47 \mathrm{mM})$ & $\mathrm{NaHCO}_{3}(40 \mathrm{mM})$ & $\mathrm{HCl}(1.5 \mathrm{mM})$ \\
\hline & $\mathrm{NaCl}(5 \mathrm{mM})$ & $\mathrm{HCl}(6.5 \mathrm{mM})$ & $\mathrm{HCl}(1.8 \mathrm{mM})$ & $\mathrm{CO}\left(\mathrm{NH}_{2}\right)_{2}(4 \mathrm{mM})$ \\
\hline & $\mathrm{NaHCO} 3(20 \mathrm{mM})$ & $\mathrm{CaCl}_{2}(2.7 \mathrm{mM})$ & $\mathrm{MgCl}_{2}(0.5 \mathrm{mM})$ & \\
\hline & $\mathrm{CO}\left(\mathrm{NH}_{2}\right)_{2}(3.3 \mathrm{mM})$ & $\mathrm{CO}\left(\mathrm{NH}_{2}\right)_{2}(1.4 \mathrm{mM})$ & $\mathrm{CO}\left(\mathrm{NH}_{2}\right)_{2}(1.7 \mathrm{mM})$ & \\
\hline enzymes & amylase $1 / 430(\mathrm{w} / \mathrm{w})$ & pepsin $1 / 40(\mathrm{w} / \mathrm{w})$ & pancreatin $1 / 50(\mathrm{w} / \mathrm{w})$ & \\
\hline $\mathrm{pH}$ & $6.8 \pm 0.2$ & $1.3 \pm 0.2$ & $8.1 \pm 0.2$ & $8.2 \pm 0.2$ \\
\hline
\end{tabular}

glucagon-like peptide 1 (GLP-1) are well-studied anorexigenic hormones. However, released GLP-1 is quickly inactivated by the dipeptidyl peptidase IV (DPP-IV). Consequently, DPP-IV represents a good target for type 2 diabetes mellitus (T2DM) management, and the search for natural DPP-IV inhibitors seems today to be a promising approach. ${ }^{16,17}$

The chicory root contains other major compounds as chlorogenic acids and sesquiterpene lactones, ${ }^{18}$ which may be of further interest. The potential synergies between inulin and these different specialized metabolites are not yet described. Consequently, we interrogated many different chicory genotypes for their metabolites composition by a proton nuclear magnetic resonance spectroscopy $\left({ }^{1} \mathrm{H}\right.$ NMR) and liquid chromatography-UV (LC-UV) for absolute quantification. Chicory roasted roots from different genotypes were next used to feed mice. Gut microbiota variations were then analyzed by NGS sequencing of 16S rRNA gene and metagenetic analysis in order to be associated with roots metabolites composition. In addition, the effects of roasted chicory on intestinal hormone modulation were investigated in vitro with the combination of simulated gastrointestinal digestion, secretion study using the STC-1 enteroendocrine cell line, and a dipeptidyl peptidase-IV (DPP-IV) inhibition assay.

\section{MATERIALS AND METHODS}

Chicory Metabolomics. Nine industrial chicory (Cichorium intybus) genotypes selected from a 48 genotype diversity field trial, conducted by Florimond-Desprez Veuve et Fils SAS (Cappelle-enPévèle, France) in year 2011 and located in Coutiches (France), were used to produce fresh chicory roots. Roots were dried and roasted by Leroux SAS (Orchies, France). Samples (roasted products) were freeze-dried $(48 \mathrm{~h})$, ground (Waring 7011G blender with glass container, Waring), and sieved to $355 \mu \mathrm{m}$. Extraction of metabolites was performed by the decoction procedure. Warm water $(100 \mathrm{~mL}, 85$ ${ }^{\circ} \mathrm{C}$ ) was added to a $150 \mathrm{~mL}$ glass tube containing $3 \mathrm{~g}$ of powder. The mixture was incubated for $20 \mathrm{~min}$ at $80^{\circ} \mathrm{C}$ under weak agitation. The solution was filtered through a coffee filter, filtrates were centrifuged at $30000 \mathrm{~g}$ for $10 \mathrm{~min}$ at $4{ }^{\circ} \mathrm{C}$, and the supernatants were store at $-80{ }^{\circ} \mathrm{C}$ until feeding. The concentration of the decoctions was normalized on the basis of dry matter to $15.5 \pm 0.5 \mathrm{mg} / \mathrm{mL}$. ${ }^{1} \mathrm{H}$ NMR absolute quantification was carried out according to Moing et al. ${ }^{19}$ by the ERETIC method using calibration curves of $\mathrm{C} 1 \mathrm{H}-(\alpha+\beta)$ glucose. ${ }^{20}$ For chlorogenic acids and sesquiterpene lactones determination, LCUV analyses were performed according to Willeman et al. ${ }^{18}$ All experiments were conducted in triplicate. Statistical analysis was performed using R 2.15.1 for Windows with FactoMineR and agricolae libraries to perform principal component analysis (PCA) and analysis of variance (ANOVA), respectively. Normality and homogeneity of the variance were checked by Shapiro-Wilk's test and Bartlett's test, respectively, followed by Tukey's test to assess significant differences between means of groups. Differences were considered significant for a $p$-value of $<0.05$.

In Vitro Simulated Gastrointestinal Digestion. In vitro simulated gastrointestinal digestion (SGID) was performed as previously described, ${ }^{21}$ with some modifications. The first three steps of digestion were simulated (mouth, stomach, and duodenum), and three fluids were prepared to mimic the physiological conditions of each step. The composition of each fluid is described in Table 1, and the $\mathrm{pH}$ of the solutions was adjusted to physiologically relevant values using $\mathrm{NaOH}(5 \mathrm{M})$ and $\mathrm{HCl}(5 \mathrm{M})$ solutions. The whole digestion process was performed in a $200 \mathrm{~mL}$ reactor controlled at 37 ${ }^{\circ} \mathrm{C}$ under constant stirring with a magnetic stirrer over $240 \mathrm{~min}$. Two $\mathrm{g}$ of chicory roasted roots (dry weight) was added to the reactor and solubilized in $16 \mathrm{~mL}$ of salivary fluids at $\mathrm{pH} 6.8\left(125 \mathrm{~g} \cdot \mathrm{L}^{-1}\right.$ dry matter $)$ containing amylase at an enzyme/substrate $(E / S)$ ratio of 1:430 (w/ $\mathrm{w})$. Sampling of $4 \mathrm{~mL}$ was performed at the end of the salivary step. Twenty-four $\mathrm{mL}$ of gastric fluids containing pepsin at an $(E / S)$ ratio of $1: 40(\mathrm{w} / \mathrm{w})$ were added after saliva sampling, and the $\mathrm{pH}$ solution was adjusted (2.5-3.0). After $2 \mathrm{~h}$, sampling of $16 \mathrm{~mL}$ was performed at the end of the gastric step (41.67 g. $\mathrm{L}^{-1}$ dry matter). Thirty-six $\mathrm{mL}$ of intestinal fluids ( $24 \mathrm{~mL}$ of duodenal juice and $12 \mathrm{~mL}$ of bile juice) containing pancreatin at an $E / S$ ratio of $1: 50(\mathrm{w} / \mathrm{w})$ and $4 \mathrm{~mL}$ of $1 \mathrm{M}$ $\mathrm{NaHCO}_{3}$ were then added to the batch, and the $\mathrm{pH}$ solution was adjusted to 7 . Intestinal digestion was carried out again over $2 \mathrm{~h}$, and sampling of $60 \mathrm{~mL}$ was performed at the end of the intestinal step. Final digest concentration reaches $13.89 \mathrm{~g} \cdot \mathrm{L}^{-1}$ dry matter. Once heated at $95{ }^{\circ} \mathrm{C}$ for $10 \mathrm{~min}$ to ensure enzyme denaturation, all samples were centrifuged at $13400 \mathrm{~g}$ for $10 \mathrm{~min}$ at room temperature. Supernatants were collected and frozen for further analysis.

CCK and GLP-1 Secretion Study. The murine enteroendocrine STC-1 cell line was a gift gratefully received from Dr. C. Roche Grangette (INSERM U865, Lyon, France). The STC-1 cells were grown at $37^{\circ} \mathrm{C}, 5 \% \mathrm{CO}_{2}$ atmosphere, in Dulbecco's modified Eagle's medium (DMEM, $4.5 \mathrm{~g} \cdot \mathrm{L}^{-1}$ glucose) supplemented with $10 \%$ fetal bovine serum (FBS), $100 \mathrm{U} \cdot \mathrm{mL}^{-1}$ penicillin, $100 \mu \mathrm{g} \cdot \mathrm{mL}^{-1}$ streptomycin, and $2 \mathrm{mM}$ glutamine. STC-1 cells were seeded to reach $60-80 \%$ confluence. Cells were washed twice with fresh media (without FBS) and incubated with 3 different concentrations (0.2, 0.5, and $1 \%(\mathrm{w} / \mathrm{v}))$ of chicory roasted roots compared to their in vitro simulated gastrointestinal digestion (SGID) products diluted in incubation buffer $\left(4.5 \mathrm{mM} \mathrm{KCl}, 1.2 \mathrm{mM} \mathrm{CaCl}, 1.2 \mathrm{mM} \mathrm{MgCl}_{2}\right.$, $140 \mathrm{mM} \mathrm{NaCl}$, and $20 \mathrm{mM}$ Hepes-Tris, $\mathrm{pH} 7.4)$ for $2 \mathrm{~h}$ at $37^{\circ} \mathrm{C}$ in $5 \%$ $\mathrm{CO}_{2}$ atmosphere. Cell supernatants were collected on ice and centrifuged $(2000 \mathrm{~g}$ for $7 \mathrm{~min}$ ). The supernatants were frozen and stored at $-20{ }^{\circ} \mathrm{C}$ for further hormone-concentration determinations. Secreted CCK and active GLP-1 concentrations (pM) in culture media of STC-1 cells were assayed using commercial RIA kits (Active Glucagon-Like Peptide RIA kit from EMD Millipore from Merck KGaA, Darmstadt, Germany, and Gastrin kit from CisBio, France).

DPP-IV Inhibition Assay. The DPP-IV inhibitory activity of the native chicory roasted roots compared to their SGID products was assayed according to the method described by Lacroix and Li-Chan ${ }^{22}$ with some modifications. Briefly, $25 \mu \mathrm{L}$ of chicory samples and their corresponding SGID products at concentrations ranging from 0.87 to $13.89 \mathrm{mg} / \mathrm{mL}$ (dry matter) were preincubated with $75 \mu \mathrm{L}$ of Tris/ $\mathrm{HCl}$ 
A

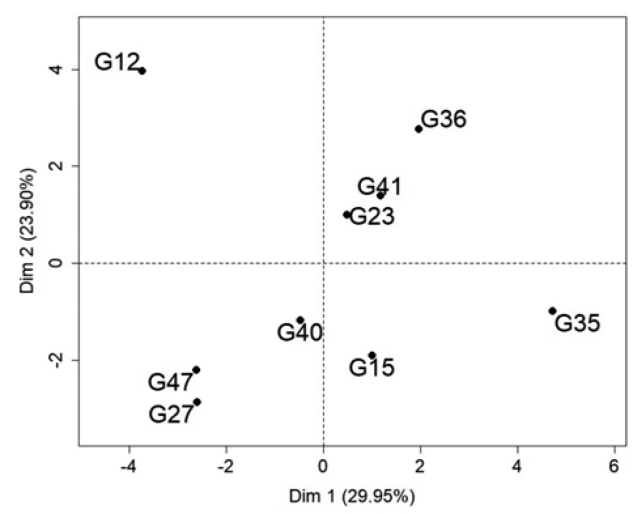

$\mathbf{B}$

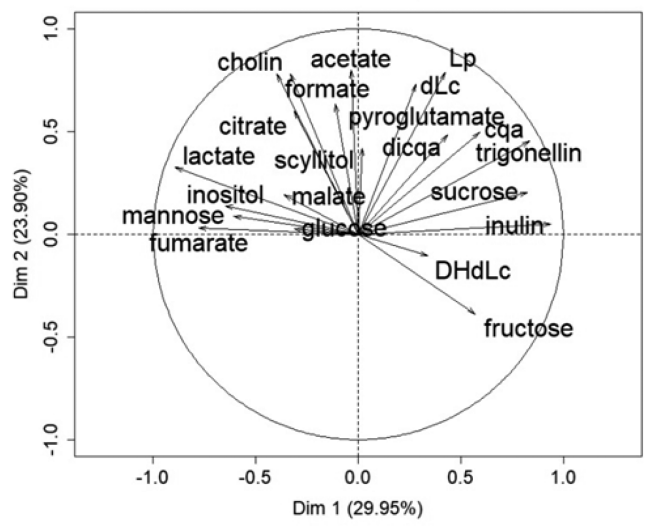

C

\begin{tabular}{|c|c|c|}
\hline \multirow{2}{*}{$\begin{array}{l}\text { Compounds ( } \mu \mathrm{g} / \mathrm{g} \\
\text { dry matter) }\end{array}$} & \multicolumn{2}{|c|}{ Genotypes } \\
\hline & G12 & G35 \\
\hline Glucose & 18.31a & 15.11a \\
\hline Fructose & $15.43 \mathrm{~b}$ & $20.65 a$ \\
\hline Sucrose & $17.91 \mathrm{~b}$ & 26.54a \\
\hline Mannose & 2.91a & $2.11 a$ \\
\hline Inulin & $105.80 \mathrm{~b}$ & $250.33 a$ \\
\hline Citrate & $6.88 a$ & $4.37 \mathrm{~b}$ \\
\hline Fumarate & $0.13 a$ & $0.08 \mathrm{~b}$ \\
\hline Malate & $3.10 a$ & $2.70 a$ \\
\hline Lactate & $0.80 a$ & $0.34 b$ \\
\hline Formate & $0.47 a$ & $0.31 b$ \\
\hline Pyroglutamate & 5.68a & $4.41 a$ \\
\hline Acetate & $0.23 a$ & $0.13 b$ \\
\hline Trigonellin & $0.053 a$ & $0.070 a$ \\
\hline Chol in & $0.47 a$ & $0.36 a$ \\
\hline Scyllitol & $0.90 a$ & $0.71 a$ \\
\hline Inositol & 3.06a & $2.08 \mathrm{~b}$ \\
\hline $\begin{array}{l}\text { 3-mono-O- } \\
\text { caffeoylquinic acid } \\
\text { (cqa) }\end{array}$ & $0.293 \mathrm{~b}$ & $0.343 a$ \\
\hline $\begin{array}{l}\text { 3,5 di-O- } \\
\text { caffeoylquinic acid } \\
\text { (dicqa) }\end{array}$ & $0.066 a$ & $0.070 a$ \\
\hline $\begin{array}{l}\text { Deoxydihydro } \\
\text { lactucin (DHdLc) }\end{array}$ & $0.011 b$ & $0.014 a$ \\
\hline Deoxylactucin (dLc) & $0.004 a$ & $0.003 a$ \\
\hline Lactucopicrin (Lp) & $0.003 a$ & $0.003 a$ \\
\hline
\end{tabular}

Figure 1. Chicory metabolites content. Principal component analysis (PCA) with individuals factor map (A) and variables factor map (B) of the LCUV and ${ }^{1} \mathrm{H}$ NMR metabolite profile differentiating roasted chicory root product of nine genotypes. Plots are based on the two first components, both explaining 53.85\% of total variance. (C) Average levels of major metabolites detected in the two selected genotypes G12 and G35. Statistically significant differences measured by ANOVA $(p<0.05)$ according to genotype are shown with different letters in the same column (Tukey's test). Roasted roots of G12 genotype present higher proportion of citrate, fumarate, lactate, formate, acetate, and inositol than those of G35 genotype. Inversely, roasted roots of G35 genotype were richer in inulin, sucrose, and fructose as well as in 3-mono-O-caffeoylquinic acid and dihydrodeoxylactucin.

buffer $(100 \mathrm{mM}, \mathrm{pH} 8.0)$ and $25 \mu \mathrm{L}$ of DPP-IV $(25 \mu \mathrm{L}$ at $0.018 \mathrm{U}$. $\left.\mathrm{mL}^{-1}\right)$ at $37^{\circ} \mathrm{C}$ for $5 \mathrm{~min}$ in a 96 -well plate. For control purposes, the sample was replaced with Tris/ $\mathrm{HCl}$ buffer $(100 \mathrm{mM}, \mathrm{pH} 8.0)$. The reaction was initiated by the addition of $50 \mu \mathrm{L}$ of Gly-Pro-pnitroanilide $(1 \mathrm{mM})$. All the samples and reagents were diluted in Tris/ $\mathrm{HCl}$ buffer. The plate was incubated at $37^{\circ} \mathrm{C}$ for $30 \mathrm{~min}$, and the absorbance of the released $p$-nitroaniline at $405 \mathrm{~nm}$ at 2 min intervals was read using a microplate reader (ELx808, Biotek, U.S.A.). The concentration of the sample required to cause $50 \%$ inhibition of the DPP-IV activity $\left(\mathrm{IC}_{50}\right)$ was determined by plotting the \% DPP-IV inhibition as a function of sample final concentration natural logarithmic.

Animal Experiments. Six-week-old female BALB/c BYj were used to evaluate the prebiotic effects of chicory in agreement with the directive 2010/63/EEC for the protection of animals used for scientific experiments and according to the law 2012-10 (2012) and 2013-118 (2013). The protocol was approved by the Ethics Committee for the experiment on animals (APAFIS 6539). The mice were randomly divided into groups $(n=5 /$ group $)$ and housed in a controlled environment (with a temperature of $22{ }^{\circ} \mathrm{C}$, a $12 \mathrm{~h} / 12 \mathrm{~h}$ light/dark cycle and ad libitum access to standardized food and water). Mice were fed with an aqueous decoction concoction (produced as described before) of the roasted powders from two selected genotypes (G12 and G35). This solution corresponded to $7 \mathrm{mg}$ of chicory roasted roots/ mouse/day, which was considered to be the human equivalent weight/ body mass for a moderated alimentary dose. The mice gavages consisted in a daily force-feeding of $500 \mu \mathrm{L}$ of stemming solution decoctions of roasted roots besides the standardized diet. Controls will undergo an equivalent force-feeding with water. Five mice by condition were used for 30 days followed by a week of resilience. Feces were individually harvested just prior to the starting of the treatment (D0), after 30 days of treatment (D30), and next to the washout period (D36). Samples were immediately frozen and preserved at $-80{ }^{\circ} \mathrm{C}$.

16S rRNA Gene Library Construction and Sequencing. Genomic DNA extraction from each fecal sample was performed with the QIAamp DNA Stool Mini Kit (kit QA) according to manufacturer's instructions. Quality and quantity of DNA extracted from fecal sample were determined using Agilent 2100 Bioanalyzer system (Agilent). Polymerase chain reaction (PCR) amplification of the $\mathrm{V} 1-\mathrm{V} 3$ region of the $16 \mathrm{~S} \mathrm{rDNA}$ and library preparation were performed with the following primers (with Illumina overhand adapters): forward (5'-GAGAGTTTGATYMTGGCTCAG-3') and reverse (5'-ACCGCGGCTGCTGGCAC-3'). Each PCR product was purified with the Agencourt AMPure XP beads kit (Beckman Coulter, Pasadena, U.S.A.) and submitted to a second PCR round for indexing, using the Nextera XT index primers 1 and 2. After purification, PCR products were quantified using the Quant-IT PicoGreen (ThermoFisher Scientific, Waltham, U.S.A.) and diluted to $10 \mathrm{ng} \mu \mathrm{L}^{-1}$. A final quantification, by qPCR, of each sample in the library was performed using the KAPA SYBR FAST qPCR kit (KapaBiosystems, Wilmington, U.S.A.) before normalization, pooling, and sequencing on a MiSeq sequencer using v3 reagents (ILLUMINA, U.S.A.). Positive control using DNA from 20 defined bacterial species and a negative control (from the PCR step) were included in the sequencing run. Sequence read processing was used as previously described using, respectively, MOTHUR software package $v 1.35^{23}$ and UCHIME algorithm ${ }^{24}$ for alignment and clustering and chimera detection. Clustering distance of 
0.03 was used for OTU generation. 16S Reference alignment and taxonomical assignation were based upon the SILVA database (v1.28) of full-length $16 \mathrm{~S}$ rDNA sequences. ${ }^{25}$ Species assignment of representative sequence for each OTU was based upon a BlastN algorithm search using SILVA v1.28 database with an identity cutoff of 0.01 . From 1938786 raw reads, we obtained 1515443 reads after cleaning (length and sequence quality). We retained 8000 reads per sample as a subsampling process, which were further screened for chimeric contaminants. Finally, 217790 reads (median: 7632 per sample) were used for OTU clustering and taxonomic assignment. Good's coverage estimator was used as a measure of sampling effort for each sample, with a mean value of $98.44 \%$. Subsample data sets were obtained and used to evaluate ecological indicators, richness estimation (Chao 1 estimator), microbial biodiversity (reciprocal Simpson index), and population evenness (derived from Simpson index) using MOTHUR. Population structure and community membership were assessed with MOTHUR using distance matrix based on Bray-Curtis dissimilarity index as a measure of community structure, which considers shared OTUs and their relative abundances. ${ }^{26}$ Ordination analysis and 3D plots were performed with Vegan, Vegan3d, and rgl packages in R. Nonmetric dimensional scaling, based upon the Bray-Curtis dissimilarity matrix, was applied to visualize the biodiversity between the groups. AMOVA test was performed to assess the diversity clustering of treatment groups with Bray-Curtis matrix using MOTHUR ${ }^{27}$ Statistical differences between bacterial biodiversity, richness, and evenness were assessed with twoway ANOVA corrected for multitesting (Benjamini, Krieger, and Yekutieli) using PRISM 7 (Graphpad Software); differences were considered significant for a $p$-value of $<0.05$. Statistical differences of population abundance between groups were assessed with ANOVA, using STAMP software. ${ }^{28}$ Statistical paired differences between treatment groups of specific bacterial populations were assessed by two-way ANOVA and Tukey-Kramerposthoc test using PRISM 7 (Graphpad Software); differences were considered significant for a $p$ value of $<0.05$. All the biosample raw reads have been deposited at the National Center for Biotechnology Information (NCBI) and are available under ID PRJNA433087. Microbial profiling was validated for the most important bacterial phyla, using quantitative PCR (Supporting Information).

\section{RESULTS}

Metabolomic Analyses in Chicory Plants. Nine industrial chicory genotypes were selected from a 48 genotype diversity field trial. This selection was performed through a genetic diversity characterization using the combination of 47 metabolomic signals and 170 alleles issued from 19 monoloci, codominant, well-dispersed on the genome as informative chicory-specific simple sequence repeat (SSR) markers (unpublished results). From 9 interrogated chicory genotypes, metabolomic analyses revealed two very distinct genotypes: G12 and G35 (Figure 1). The G12 genotype presented significantly more citrate, fumarate, lactate, formate, acetate, and inositol than G35. Inversely, roasted roots of G35 genotype where richer in inulin, sucrose, and fructose as well as in 3mono-O-caffeoylquinic acid and dihydrodeoxylactucin. G12 and G35 genotypes were selected and used for mice feeding in order to observe modifications at the gut microbiota level.

In Vitro Gut Hormone Regulation. The roasted roots were predigested using SGID to mimic the first three compartments of the gastrointestinal tract, in order to compare the effects of the roots from two different genotypes. The samples for which SGID was not undertaken were incubated alongside the duodenal digests for $2 \mathrm{~h}$ with the STC-1 cells. Results showed that each genotype exerted a significant dosedependent stimulation of CCK release before and after SGID, and interestingly, the SGID treatment led to an increase in the CCK release for the G12 and the G35 genotypes (Figure 2A).

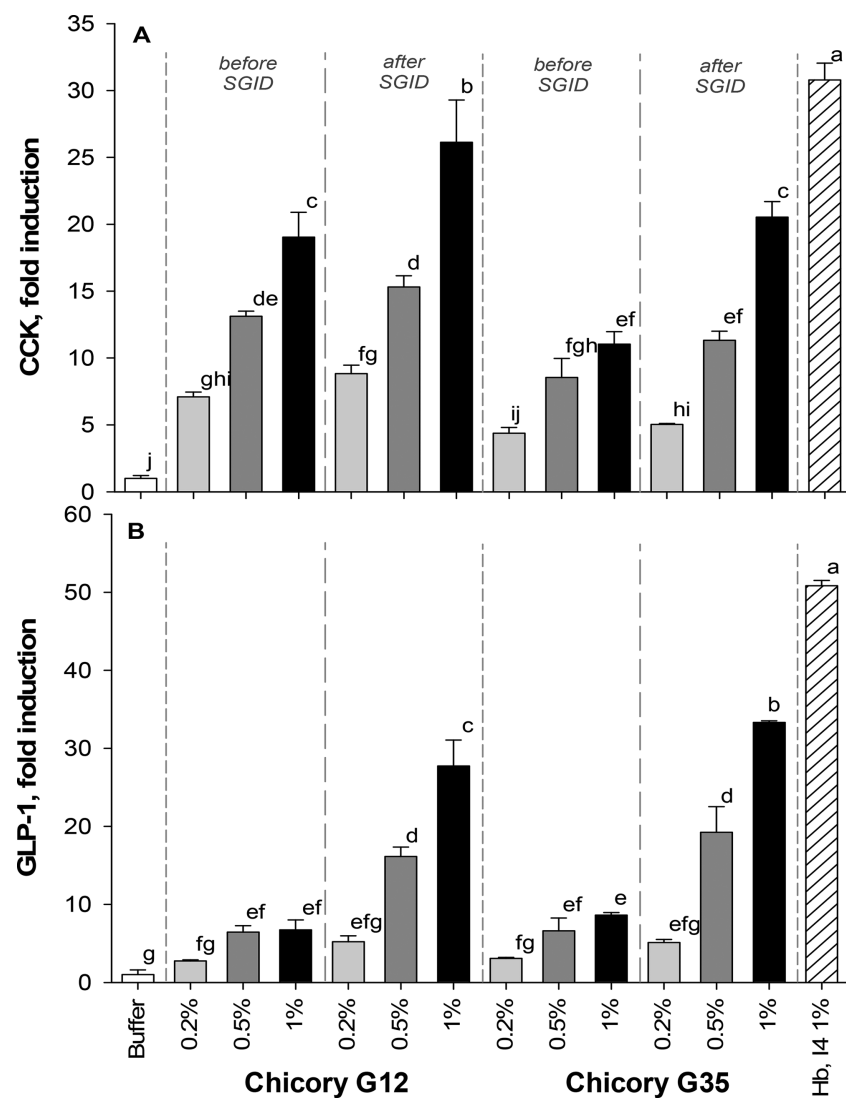

Figure 2. Effect of chicory roasted roots on intestinal hormone secretion by STC-1 cells. STC-1 cells were incubated with different final concentrations $(0.2,0.5$, and $1 \%$ dry matter) of chicory roasted roots (G12 and G35 genotype), before and after SGID, in Hepes buffer, $\mathrm{pH}$ 7.4. Bovine hemoglobin intestinal hydrolysate $(\mathrm{Hb}, \mathrm{I} 4,1 \%$ dry matter final concentration) was used as positive control. Supernatants were collected after $2 \mathrm{~h}$ of incubation. (A) Cholecystokinin (CCK) and (B) glucagon-like peptide-1 (GLP-1) levels were determined by RIA and expressed as \% of control (buffer) levels. Data are expressed in mean $(n=3) \pm$ SD. Means without a common letter are different $(p<0.05)$ using one-way ANOVA with Tukey's test for pairwise comparisons.

These increases were significant for the highest dose assayed $(1 \% \mathrm{w} / \mathrm{v})$ and represented 20 - and 25 -fold the value of the control (buffer), respectively. In comparison, the hemoglobin digest, which was previously described as a strong stimulator of CCK release $^{21}$ and used here as positive control, led to an increase of 30 -fold of control.

The impact of SGID on the stimulation potential of GLP-1 secretion observed was significant (Figure 2B). Thus, the effects of the roasted roots before SGID on GLP-1 secretion were relatively weak and similar for the G12 and the G35 genotypes but significant compared to control (6- and 8.5-fold of control for the two highest doses). After the SGID treatment, a dosedependent increase on GLP-1 release, significant for 0.5 and $1.0 \% \mathrm{w} / \mathrm{v}$, was observed for the G12 and G35 genotypes (28and 33-fold of control, respectively). At the same dose, the positive control, i.e., the hemoglobin digest, led to a 50-fold increase in GLP-1 release. Moreover, the DPP-IV inhibition capacities of the different roasted roots samples before and after SGID were assayed. No significant inhibition of the DPP-IV activity could be observed for any of the samples (data not shown). 

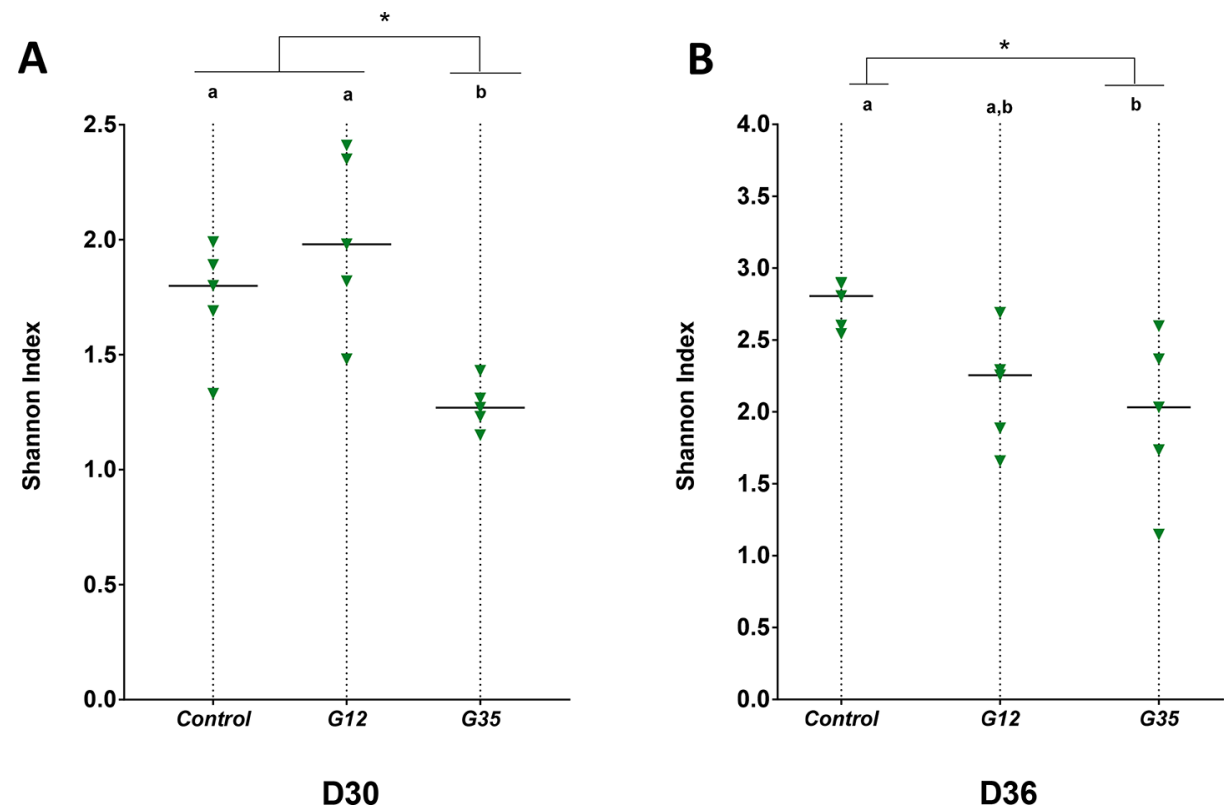

Figure 3. Shannon index of bacterial diversity during different chicory diets. G35 chicory triggered the most reduced bacterial diversity in fecal samples after 30 days of diet (D30). After the washout period (D36), both chicory genotypes indicate a decreased level of $\alpha$-diversity compared to control. Significant differences $(p<0.05)$ are indicated with letters $(\mathrm{a}, \mathrm{b})$; * indicates $p<0.05$.

Table 2. Mean Relative Abundances (\%) of Bacterial Phyla in Mice Microbiota During Different Chicory Diets (D30) ${ }^{a}$

\begin{tabular}{|c|c|c|c|c|c|c|}
\hline \multirow[b]{2}{*}{ phylum } & \multicolumn{2}{|c|}{ control } & \multicolumn{2}{|c|}{ G12 } & \multicolumn{2}{|c|}{ G35 } \\
\hline & mean $(\%)$ & $\mathrm{SD}$ & mean $(\%)$ & SD & mean $(\%)$ & $\mathrm{SD}$ \\
\hline Bacteroidetes & 85.593 a & 5.114 & 83.646 a & 3.960 & $96.500 \mathrm{~b}$ & 1.256 \\
\hline Firmicutes & $14.131 \mathrm{a}$ & 5.155 & $15.670 \mathrm{a}$ & 3.760 & $3.122 \mathrm{~b}$ & 1.209 \\
\hline Verrucomicrobia & 0.018 & 0.022 & 0.066 & 0.099 & 0.032 & 0.053 \\
\hline Proteobacteria & 0.042 & 0.032 & 0.023 & 0.029 & 0.169 & 0.032 \\
\hline Cyanobacteria & 0.150 & 0.140 & 0.464 & 0.225 & 0.141 & 0.064 \\
\hline Tenericutes & 0.046 & 0.032 & 0.089 & 0.091 & 0.023 & 0.035 \\
\hline Actinobacteria & 0.009 & 0.011 & 0.000 & 0.000 & 0.004 & 0.008 \\
\hline Deferribacteres & 0.000 & 0.000 & 0.000 & 0.000 & 0.000 & 0.000 \\
\hline TM7 & 0.009 & 0.018 & 0.042 & 0.031 & 0.000 & 0.000 \\
\hline Fusobacteria & 0.000 & 0.000 & 0.000 & 0.000 & 0.009 & 0.010 \\
\hline
\end{tabular}

${ }^{a}$ Standard deviations (SD) were calculated for each phylum abundance, and statistically significant differences were measured by ANOVA $(p<0.05)$ and are shown with different letters (Tukey's test).

Metagenetic Analyses in Chicory-Treated Mice. Roasted roots of G12 and G35 chicory genotypes were used for 30 days of daily supplementary dietary feeding of mice at $350 \mathrm{mg} \cdot \mathrm{kg}^{-1}$, a concentration estimated to be proportional to human daily consumption. No significant difference on the body weights of mice was found after treatments and after the washout period (Supporting Information). Fecal samples from mice before and after 30 days of chicory feeding and after the 1week washout were used for DNA extraction and 16S rRNA gene sequencing in order to perform a metagenetic analysis.

The microbial $\alpha$-diversity within each group (G12, G35, and control) was quantified for each treatment range. Composed of scores between 0 and 5, the Shannon index (SI) represents a synthetic numerical value of the ecological $\alpha$-diversity of the microbiota in each fecal sample, a higher SI indicating a greater diversity. A significant decrease in SI was observed after 30 days of treatment with G35 (Figure 3A), suggesting that the effect on microbiota could be dependent on the dietary chicory genotype. After the washout period (D36), both chicory genotypes seemed to maintain a decreased level of $\alpha$-diversity compared to control (Figure 3B).

Chicory-dependent microbiota profile was next explored at the phylum level (Table 2). Four weeks of chicory diet induced several changes in the gut microbial community at the phylum level compared with the control (no-treated mice). The relative abundance of Firmicutes was less changed in G12-treated mice $(15.6 \%$ vs $14.1 \%)$ but greatly reduced in G35-treated mice (3.1\% vs $14.1 \%)$. The Bacteroidetes phylum was also less modified in the G12 group ( $83.6 \%$ vs $85.5 \%$ ) but increased in the G35 group (96.5\% vs $85.5 \%$ ). Other phyla showed low variations during chicory treatment, $<1 \%$. In addition, the ratio of Firmicutes (F) to Bacteroidetes (B) was higher in G12treated mice and significantly lower in G35-treated mice compared to the control ( 0.187 to 0.032 vs 0.165 ) (Figure 4 ). qPCR analyses on three different feces samples confirmed this result (Supporting Information).

At the genus level, all changes observed in the relative abundance after 30 days of chicory treatment are represented in Figure 5 and the Supporting Information. Beta diversity among 


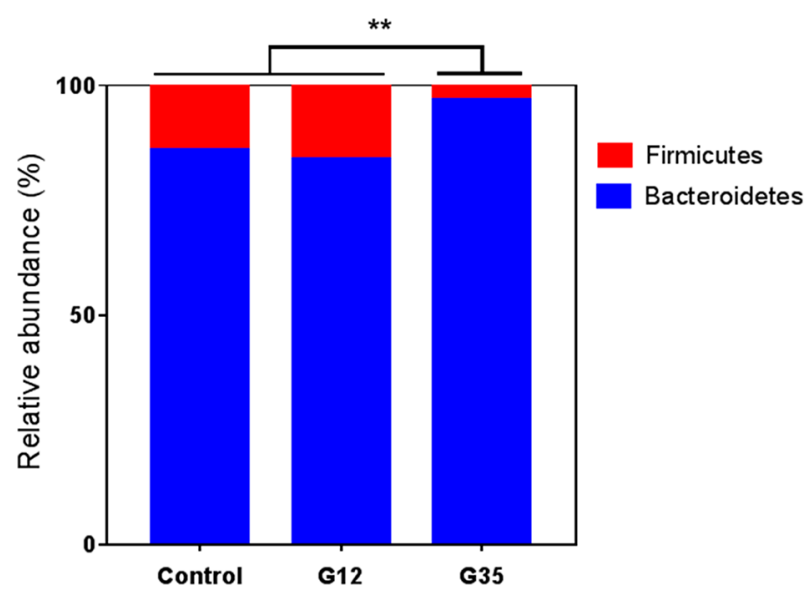

Figure 4. Relative abundance (\%) of Firmicutes and Bacteroidetes in mice microbiota after chicory diet. Relative abundance of phyla Firmicutes and Bacteroidetes detected by NGS is expressed as a mean (Tukey's test, $n=5 /$ group, $* *$ indicates $p<0.01$ ).

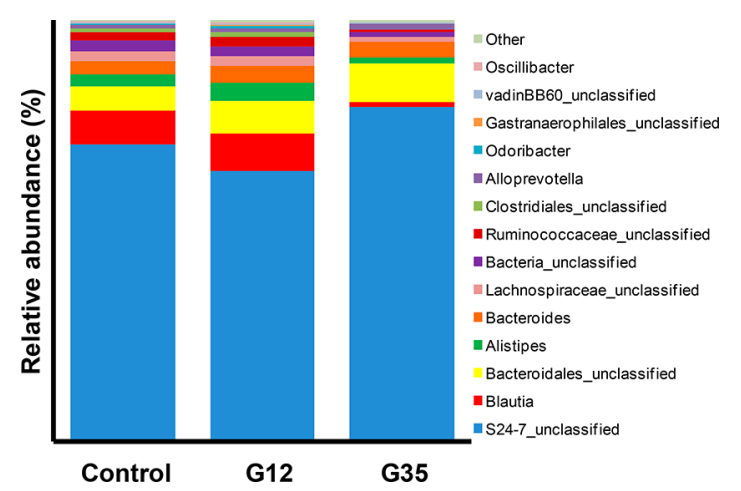

Figure 5. Relative abundance (\%) of main genera in mice fecal microbiota after chicory diet. Relative abundance of genera are indicated when their values are $>0.1 \%$. Genera with a low relative abundance were assigned as "other". different conditions as a measure of genera turnover was considered by factorial correspondence analysis (FCA) (Figure 6 ) and showed a specific distribution of the significant bacterial genera abundances around each chicory treatment. Two taxa seemed to be more associated with the G35 treatment: Bacteroidales unclassified and Alloprevotella, as they present a significantly increased abundance in G35 treatment. Six other taxa, Ruminococcaceae unclassified, Alistipes, Oscillibacter, Lachnospiraceae unclassified, Blautia, and Clostridiales unclassified, showed an important decrease in the G35 group (Supporting Information). The significant variations in classified taxa were compared to controls after 30 days (Figure 7). Alloprevotella relative abundance increased while abundance of Alistipes, Blautia, and Oscillibacter decreased during G35 chicory feeding.

\section{DISCUSSION}

Many studies have already been done on the inulin of chicory and its prebiotic effect. Our work was oriented toward a new analytical dimension. The composition of roasted roots of chicory was considered for the first time by all major metabolic compounds and also by the variability of these compounds. We tested the effects of the roasted products of chicory on the intestinal microbiota of mice, and these tests were performed for the first time on murine model. There are no safe or effective doses established for chicory consumption in humans as yet, but common doses that have been traditionally used range from 3 to $6 \mathrm{~g}$ of chicory root per day. ${ }^{29,30}$ Taking this into account, $7 \mathrm{mg}$ of roasted roots/mouse/day was used, which was considered to be the equivalent of a moderated human alimentary dose. We then analyzed the daily feeding consequences on mice gut microbiota composition and, in parallel, the in vitro effects on two satiety hormones. All results were then converged to be finally associated with the metabolite composition of each chicory genotype in order to estimate their effect as prebiotic and on appetite control.

Chicory Genotypes Contain Different Metabolites Proportions. G12 and G35 chicory genotypes contain carboxylic compounds such as citrate, fumarate, lactate,

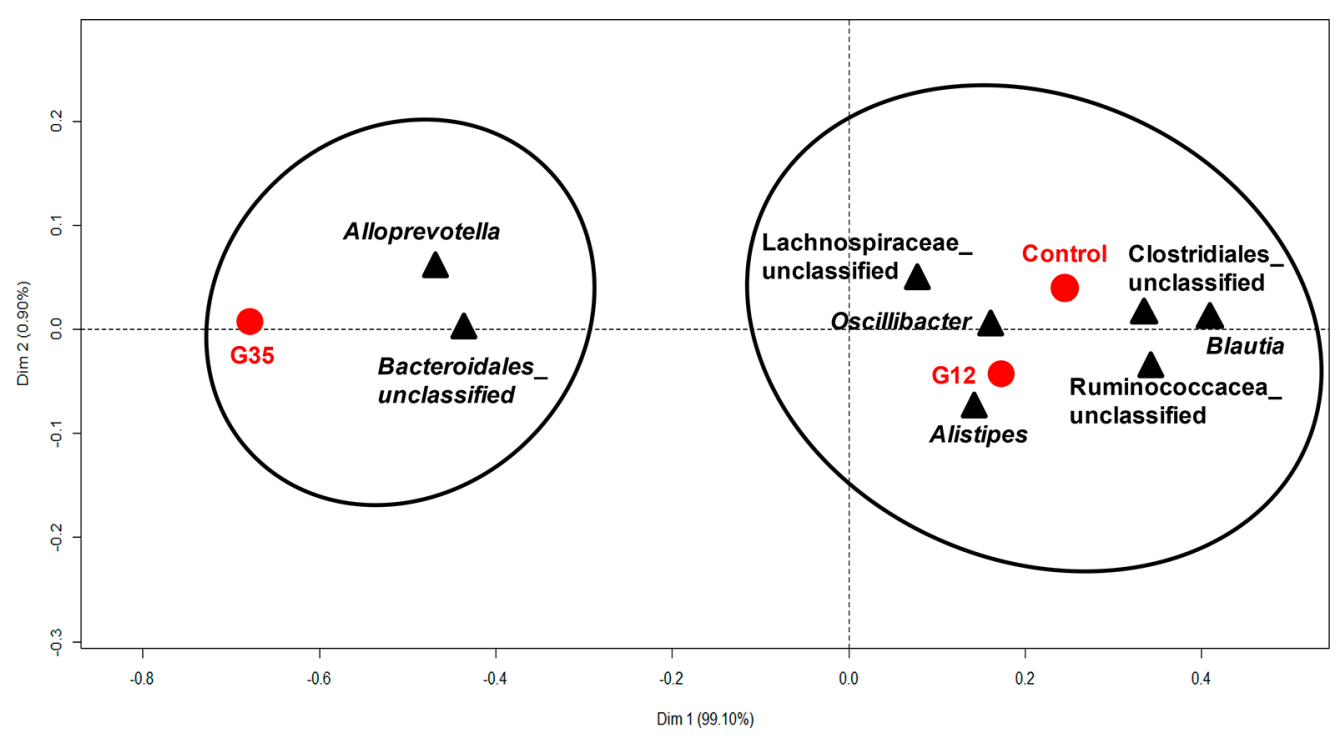

Figure 6. Factorial correspondence analysis (FCA) of the significant abundant bacterial genera. FCA was used to describe variability among genera abundance ( 8 must abundant genera were used as variables, black letters) in the two analyzed chicory genotypes G12 and G35 (used as factors, red letters). The commonality created around the chicory G12 seems richer than those of G35. A genotype-dependent effect could be observed (the two rings). 

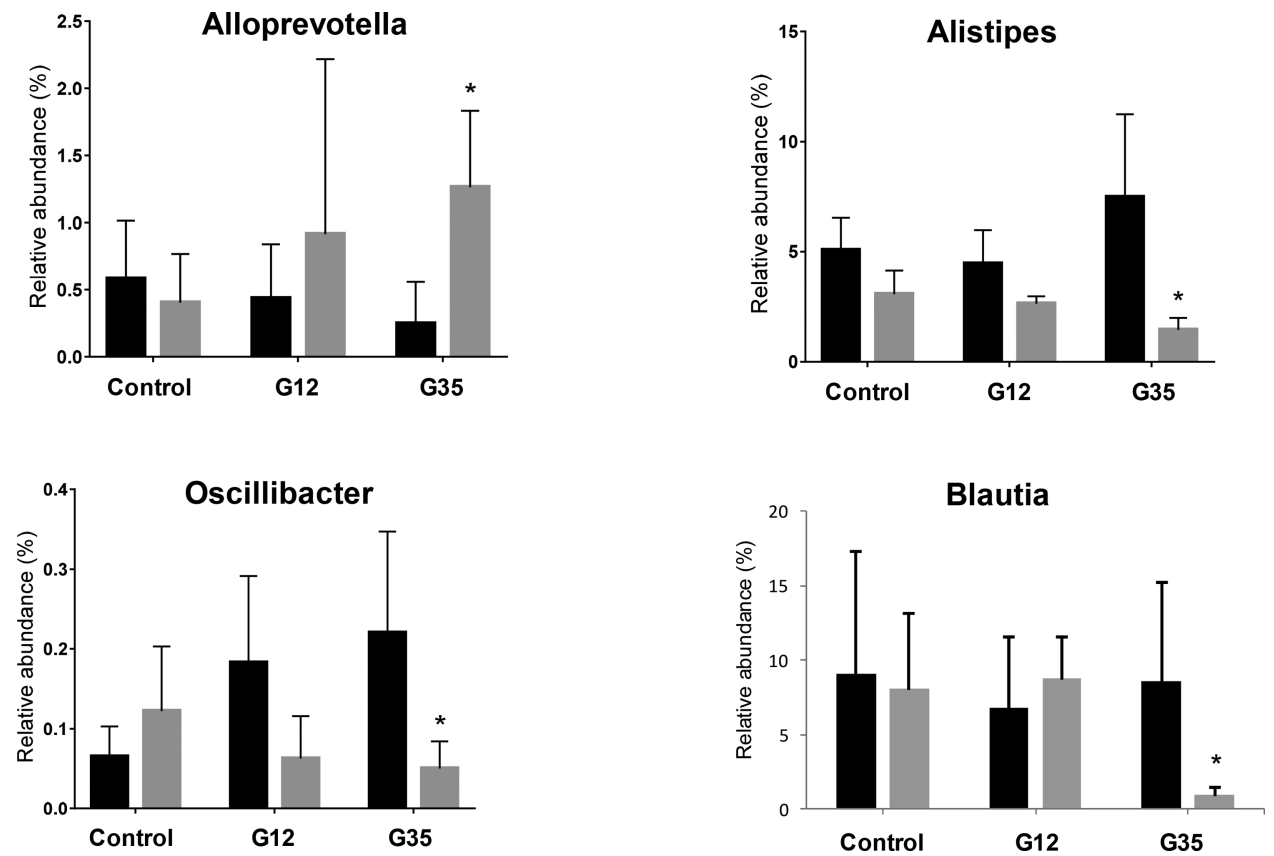

Figure 7. Significant variations in four genera of mice microbiota after chicory diet. Bar graphs compare relative abundance of each condition between D0 and D30 for the most significant genera variations analyzed by NGS and metagenetics. Relative abundance is expressed as mean \pm SD (* indicates $P<0.05$, Student's $t$ test, $n=5$ /group).

formate, or acetate, but a significant increasing amount of these was observed for G12 (Figure 1). Lactate and citrate could contribute to acetate production, ${ }^{31-33}$ known as a short-chain fatty acid (SCFA). ${ }^{34}$ An important source of SCFAs is also inulin. This fermentable carbohydrate is a soluble dietary fiber that is present in noticeable amounts in chicory roots. In our experiments, inulin content of both chicory genotypes are elevated, with a significant increased amount for G35, representing $236.6 \%$ more inulin than G12. Similarly, fructose and sucrose contents were found to be significantly increased in G35 (Figure 1). It was demonstrated that supplementation of inulin resulted further in significantly elevated concentrations of total SCFAs in the cecum with positive effects on lipid metabolism and obesity development. ${ }^{35}$ Fructose indirectly contributed to the formation of SCFAs because of its presence in fructans and fructooligosaccharides (FOS) that generate SCFAs under microbiota fermentation. ${ }^{36}$

Either ingested with food or produced by gut microbiota metabolism, SCFAs are then absorbed and used in different biosynthetic routes by the host, entering diverse carbohydrate and lipid metabolic pathways. The involvement of SCFAs in energy and lipid metabolism has largely been analyzed, and the potential role of SCFAs in the control of metabolic syndrome has also been observed and discussed in the literature. Butyrate and propionate have been reported to induce the production of the glucagon-like peptide-1 (GLP-1) gut hormone, thus reducing food intake. ${ }^{37}$ Acetate has also been found to reduce the appetite, but mainly through the interaction with the central nervous system, by a hypothalamic mechanism involved in the control of body weight. ${ }^{38}$

Chlorogenic acids were detected in roasted chicory roots with a significant increased concentration for 3-mono- $O$ caffeoylquinic acid (cqa) in G35 (Figure 1). Chlorogenic acids refer to a related polyphenol family of esters that can play a role in blood-pressure reduction ${ }^{39,40}$ and have potential antiinflammatory effects. ${ }^{41}$
Another group of biologically active compounds in chicory are sesquiterpene lactones (SLs). SLs possess anti-inflammatory and antitumor activity and are the main determinants of bitterness. Control of their concentrations is a key point for the market value of different chicory varieties. ${ }^{42}$ Among SLs we noticed that the amount of $11 \beta, 13$-dihydro-8-deoxylactucin (DHdLc) varied significantly between chicory genotypes (Figure 1), as G35 is richer in DHdLc than G12.

To conclude, we focused on the most significant differences between G12 and G35 chicory genotypes. The G35 roasted roots contained a higher amount of fermentable carbohydrates (inulin and fructose) that are considered as SCFA generators during colon digestion and present a potential satiety control by different digestive mechanisms. G12 roasted roots showed less fermentable carbohydrate content than G35 but an increased amount of acetate, which is involved also in the control of body weight. Moreover, G35 showed an increased content of anti-inflammatory compounds as cqa and DHdLc. Taking into account these significant differences, we then addressed one further question, whether the feeding with G12 and G35 chicory roots has different effects on the production of satiety hormones and on gut microbiota composition.

Satiety Hormones Increase Is Dependent on Chicory Genotype. To the best of our knowledge, this is the first work to describe the effect of chicory on the regulation of gut hormones in vitro. Thus, the results obtained highlight for the first time the capability of roasted chicory roots to enhance both CCK and GLP-1 secretion in EECs. Interestingly, SGID enhances the ability to induce both CCK and GLP-1 secretion for the G12 and G35 genotypes. Considering the small intestine compartment of the SGID, the effects obtained on CCK and GLP-1 secretion with G35 and G12 are very significant when compared to those obtained for the hemoglobin intestinal digest (used as positive control), which was previously reported to be a strong stimulator of gut hormone secretion. ${ }^{21}$ Interestingly, the bioactivities were 
impacted by the genotype; the G12 was more efficient to induce CCK secretion, whereas G35 was more potent for GLP1 secretion. This is presumably due to the difference observed in the metabolite composition of the two genotypes as commented on earlier and shown in Figure 1. Thus, it is well-known that carbohydrates such as glucose and fructose are strong stimulators of gut hormone secretion. ${ }^{43}$ Moreover, recently an increasing number of works have shown the implication of polyphenols in energy homeostasis as potent stimulators of gut hormone secretion and/or inhibitors of DPPIV activity. ${ }^{44,43}$ These properties together with the previously described effect of inulin and oligofructose on satiety, via its action on gut microbiota, ${ }^{46}$ make chicory a very promising ingredient for testing for effects on obesity and T2DM in different experimental assays.

Diversity of the Gut Microbiota Changes with Chicory Genotype. Daily feeding with G12 and G35 genotypes of roasted chicory equivalent to a human moderated alimentary dose triggered changes in $\alpha$-diversity, as indicated in Figure 3. At this level of analysis, the microbial community diversity alone does not necessarily provide understanding of community function, as was observed for other studies, ${ }^{49}$ but indicates a genotype-specific effect of the chicory feeding. The fact that the SI sustainably decreased in mice microbiota during G35 diet suggests that the composition of different specific metabolites of the G35 chicory genotype could probably more rapidly alter the gut microbiota.

Composition of the Gut Microbiota Changes with Chicory Genotype. The ratio between the Firmicutes and Bacterioidetes phyla was calculated for different chicory treatments, and a genotype-dependent effect was observed (Figure 4). The G35 genotype, which is richer in inulin and fructose, led to a decrease in the abundance of Firmicutes and a significant lower $\mathrm{F} / \mathrm{B}$ ratio. A change of $\mathrm{F} / \mathrm{B}$ ratio may be important in itself because this can influence the efficiency of processing of otherwise indigestible complex polysaccharides in the diet. In our pilot study, roasted chicory roots were used for feeding mice for a short period (30 days), and body weight was not significantly altered (Supporting Information), while a small decrease in body weight was observed for G35 feed mice. It was observed that diet-inducing obesity triggered changes in the $\mathrm{F} / \mathrm{B}$ ratio as the abundance of Firmicutes dramatically increased within the distal gut microbiota. ${ }^{48}$ This ratio was found also to be significantly increased in patients developing type 1 diabetes. ${ }^{49}$ Parnell and Reimer ${ }^{50}$ demonstrated a significant shift in the Bacteroidetes and Firmicutes groups with increasing doses of prebiotic fiber intake; $\mathrm{F} / \mathrm{B}$ was thus reduced with beneficial effects on obesity physiopathology. Presently, changes in intestinal microbial composition are thought to be an important causal factor in the development of obesity. ${ }^{51}$ Animal data and human studies have reported that the overall $\mathrm{F} / \mathrm{B}$ proportion is increased in obese people compared to lean people. ${ }^{52,53}$ However, this criterion is not consistent to our study design. In this context, we observed an effect of the G35 chicory genotype, which must be further investigated in different analogous models or in human subjects in order to specify the metabolic action related to diabetes and obesity.

Daily feeding with roasted chicory triggered changes in the relative abundance of several bacterial genera also (Figure 5). FCA was used to select the genotype-specific bacterial genera (Figure 6). Thus, the abundance of Alloprevotella was found to be increased in all chicory-treated groups and significantly increased in G35 treatment. The abundance of Blautia, Alistipes, and Oscillibacter was found to be significantly decreased in G35 treatments (Figure 7).

Alloprevotella belongs to Prevotelaceae family that was recently associated with an important role in gut-brain interactions as well as in metabolic disorders. Furthermore, low levels of Prevotellaceae have been reported in patients with autism ${ }^{54}$ but also in patients with type 1 diabetes. ${ }^{55}$ The mean abundance of Prevotellaceae in the feces of patients with Parkinson disease was reduced by $77.6 \%$ in comparison with control subjects. ${ }^{56}$ On the basis of these observations, high fecal abundance of Prevotellaceae was proposed as a useful biomarker to exclude Parkinson disease. ${ }^{56}$

Blautia is a genus in the bacterial family Lachnospiraceae that participates in nutrient assimilation. ${ }^{57}$ An increased abundance of Blaudia has been observed during antibiotic administration, ${ }^{58}$ giving reason to believe that this bacterial genus could be involved in antagonistic relationships at the gut microbial ecosystem level. The change in abundance must be correlated to other imbalanced bacterial groups and be specifically associated with a particular diet ${ }^{59}$ or pathology ${ }^{60}$ on a caseby-case basis.

Alistipes is a genus belonging to the Bacteroidetes phylum and was observed to be significantly correlated with autism disorders. Thus, decreased levels of ileal serotonin in the intestinal epithelial cell layer were associated with an increased abundance of the Alistipes genus. ${ }^{61}$

Oscillibacter belongs to the Clostridia class of Firmicutes, and in human gut microbiota it grows fermentatively, producing predominantly valerate when grown using glucose as a carbon source. ${ }^{62}$ Valeric acid is similar in structure to GBH $(\gamma$ hydroxybutyric acid) and GABA ( $\gamma$-aminobutyric acid), which are involved in neurotransmission in the mammalian central nervous system. Increasing abundance of Alloprevotella and decreasing Blautia, Alistipes, and Oscillibacter levels during chicory feeding could be further more closely correlated to these putative neurological effects and/or metabolic disorders.

In conclusion, we investigated many different chicory genotypes for their content of metabolites, and two genotypes, G12 and G35, were retained for their different compositions. The most important differences concerned amounts of fermentable carbohydrates (inulin and fructose), carboxylic compounds such as acetate, chlorogenic acids such as cqa, and sesquiterpene lactones (for example, DHdLc). In the literature, the majority of chicory analyses use the different compounds that are isolated and employed for targeted investigations. We did not extract isolated compounds but rather used chicory roasted roots from G12 and G35 genotypes as part of the food matrix to feed mice in order to analyze satiety hormones as well as variations in the gut microbiota. Because chicory treatments were performed with moderate quantities of roasted roots and because the two investigated chicory genotypes belong to the same species, no qualitative differences were observed in microbiome bacterial abundance. However, a genotype-dependent effect was observed. The G35 chicory genotype, which is richer in fermentable carbohydrates and also in antiinflammatory compounds such as cqa and DHdLc, could more rapidly alter the gut microbiota $\alpha$-diversity. Also, a significant change in $\mathrm{F} / \mathrm{B}$ ratio was generated by the G35 intake. CCK and GPL-1 secretion were found to be increased by the samples obtained after in vitro digestion of chicory for both genotypes, with G35 inducing the most significant increase of GLP-1. These observations explain for the first 
time the potential of chicory products in appetite control by inducing increased levels of satiety hormones. With the aim of defining the benefits of chicory for functional food, further studies must therefore be targeted through investigating microbiota composition and intestinal hormone levels in association with metabolomic composition of chicory, for a more detailed understanding of appetite-regulation mechanisms conferred by this plant. The abundance of Alloprevotella, Blautia, Alistipes, and Oscillibacter in the gut microbiota was also found to be modified during G35 chicory feeding. As these bacterial genera were described as neuroprotective or associated with gut-brain axis, there could be an interesting perspective to open for testing the psychobiotic effect of different chicory genotypes.

\section{ASSOCIATED CONTENT}

\section{S Supporting Information}

The Supporting Information is available free of charge on the ACS Publications website at DOI: 10.1021/acs.jafc.8b01055.

Microbial profiling using quantitative PCR; body weight of mice during chicory feeding; changes in the relative abundance of bacterial genera after daily feeding with roasted chicory roots; and changes in the relative abundance of significant and genotype-specific bacterial genera after daily feeding with roasted chicory roots (PDF)

\section{AUTHOR INFORMATION}

\section{Corresponding Author}

*E-mail: Anca.Lucau@univ-lille1.fr.

\section{ORCID}

Anca Lucau-Danila: 0000-0002-9379-6241

\section{Funding}

The work was funded by the University of Lille and has been carried out in the framework of Alibiotech project, which is financed by European Union, French State, and the French Region of Hauts-de-France.

\section{Notes}

The authors declare no competing financial interest.

\section{ACKNOWLEDGMENTS}

The authors wish to thank Florimond Desprez SA and Leroux for providing genetic material and roasted products. Metabolomic characterization of the genotypes was part of the Qualichic program (2013-2017). The ${ }^{1} \mathrm{H}$ NMR analyses were performed at the Metabolome Facility-MetaboHUB of Bordeaux Functional Genomic Center.

\section{REFERENCES}

(1) Shoaib, M.; Shehzad, A.; Omar, M.; Rakha, A.; Raza, H.; Sharif, R. H.; Shakeel, A.; Ansari, A.; Niazi, S. Inulin: Properties, health benefits and food applications. Carbohydr. Polym. 2016, 147, 444-454.

(2) Roberfroid, M. B. Inulin-type fructans: functional food ingredients. J. Nutr. 2007, 137 (11), 2493S-2502S.

(3) Coussement, P. A. A. Inulin and oligofructose: Safe intakes and legal status. J. Nutr. 1999, 129, 1412S-1417S.

(4) Karimi, R.; Azizi, M. H.; Ghasemlou, M.; Vaziri, M. Application of inulin in cheese as prebiotic, fat replacer and texturizer: A review. Carbohydr. Polym. 2015, 119, 85-100.

(5) Liu, J.; Luo, D.; Li, X.; Xu, B.; Zhang, X.; Liu, J. Effects of inulin on the structure and emulsifying properties of protein components in dough. Food Chem. 2016, 210, 235-241.
(6) Latoch, A.; Glibowski, P.; Libera, J. The effect of replacing pork fat of inulin on the physicochemical and sensory quality of guinea fowl pate. Acta Sci. Pol., Technol. Aliment. 2016, 15 (3), 311-320.

(7) Singer, J. M. D.; Grinev, M. R. N.; Silva, V. M. S.; Cohen, J. M. D.; Singer, P. M. D. Safety and efficacy of coffee enriched with inulin and dextrin on satiety and hunger in normal volunteers. Nutrition 2016, 32, 754-760.

(8) Halnes, I.; Baines, K. J.; Berthon, B. S.; MacDonald-Wicks, L. K.; Gibson, P. G.; Wood, L. G. Soluble Fibre Meal Challenge Reduces Airway Inflammation and Expression of GPR43 and GPR41 in Asthma. Nutrients 2017, 9, 57.

(9) Kelly-Quagliana, K. A.; Nelson, P. D.; Buddington, R. K. Dietary oligofructose and inulin modulate immune functions in mice. Nutr. Res. (N. Y., NY, U. S.) 2003, 23 (2), 257-267.

(10) Hasler, C. M. A new look at an ancient concept. Chem. Ind. 1998, 2, 84-89.

(11) Menne, E.; Guggenbuhl, N.; Roberfroid, M. Fn-type chicory inulin hydrolysate has a prebiotic effect in humans. J. Nutr. 2000, 130, 1197-1199.

(12) Gibson, G. R.; Hutkins, R.; Sanders, M. E.; Prescott, S. L.; Reimer, R. A.; Salminen, S. J.; Scott, K.; Stanton, C.; Swanson, K. S.; Cani, P. D.; Verbeke, K.; Reid, G. Expert consensus document: The International Scientific Association for Probiotics and Prebiotics (ISAPP) consensus statement on the definition and scope of prebiotics. Nat. Rev. Gastroenterol. Hepatol. 2017, 14 (8), 491-502.

(13) Bragg, L.; Tyson, G. W. Metagenomics using next-generation sequencing. Methods Mol. Biol. 2014, 1096, 183-201.

(14) Rønnestad, I.; Akiba, Y.; Kaji, I.; Kaunitz, J. D. Duodenal luminal nutrient sensing. Curr. Opin. Pharmacol. 2014, 19, 67-75.

(15) Gribble, F. M.; Reimann, F. Enteroendocrine cells: chemosensors in the intestinal epithelium. Annu. Rev. Physiol. 2016, 78, 277299.

(16) Caron, J.; Domenger, D.; Dhulster, P.; Ravallec, R.; Cudennec, B. Protein Digestion-Derived Peptides and the Peripheral Regulation of Food Intake. Front. Endocrinol. 2017, 8, 85.

(17) Nongonierma, A. B.; FitzGerald, R. J. Enhancing bioactive peptide release and identification using targeted enzymatic hydrolysis of milk proteins. Anal. Bioanal. Chem. 2018, 410, 3407.

(18) Willeman, H.; Hance, P.; Fertin, A.; Voedts, N.; Duhal, N.; Goossens, J. F.; Hilbert, J. L. A Method for the Simultaneous Determination of Chlorogenic Acid and Sesquiterpene Lactone Content in Industrial Chicory Root Foodstuffs. Sci. World J. 2014, 2014, 1-11.

(19) Moing, A.; Maucourt, M.; Renaud, C.; Gaudillere, M.; Brouquisse, R.; Lebouteiller, B.; Gousset-Dupont, A.; Vidal, J.; Granot, D.; Denoyes-Rothan, B.; Lerceteau-Kohler, E.; Rolin, D. Quantitative metabolic profiling by 1-dimensional 1H-NMR analyses: application to plant genetics and functional genomics. Functional Plant Biology 2004, 31, 889-902.

(20) Akoka, S.; Barantin, L.; Trierweiler, M. Concentration Measurement by Proton NMR Using the ERETIC Method. Anal. Chem. 1999, 71 (13), 2554-2557.

(21) Caron, J.; Cudennec, B.; Domenger, D.; Belguesmia, Y.; Flahaut, C.; Kouach, M.; Lesage, J.; Goossens, J. F.; Dhulster, P.; Ravallec, R. Simulated GI digestion of dietary protein: Release of new bioactive peptides involved in gut hormone secretion. Food Res. Int. 2016, 89, $382-390$.

(22) Lacroix, I. M.; Li-Chan, E. C. Evaluation of the potential of dietary proteins as precursors of dipeptidyl peptidase (DPP)-IV inhibitors by an in silico approach. J. Funct. Foods 2012, 4, 403-422.

(23) Schloss, P. D.; Westcott, S. L.; Ryabin, T.; Hall, J. R.; Hartmann, M.; Hollister, E. B.; Lesniewski, R. A.; Oakley, B. B.; Parks, D. H.; Robinson, C. J.; Sahl, J. W.; Stres, B.; Thallinger, G. G.; Van Horn, D. J.; Weber, C. F. Introducing mothur: open-source, platformindependent, community-supported software for describing and comparing microbial communities. Appl. Environ. Microbiol. 2009, $75,7537-7541$. 
(24) Edgar, R. C.; Haas, B. J.; Clemente, J. C.; Quince, C.; Knight, R. UCHIME improves sensitivity and speed of chimera detection. Bioinformatics 2011, 27 (16), 2194-200.

(25) Quast, C.; Pruesse, E.; Yilmaz, P.; Gerken, J.; Schweer, T.; Yarza, P.; Peplies, J.; Glöckner, F. O. The SILVA ribosomal RNA gene database project: improved data processing and web-based tools. Nucleic Acids Res. 2012, 41, D590-D596.

(26) Bray, J. R.; Curtis, J. T. An ordination of upland forest communities of southern Wisconsin. Ecol. Monogr. 1957, 27, 325-349.

(27) Martin, A. P. Phylogenetic approaches for describing and comparing the diversity of microbial communities. Appl. Environ. Microbiol. 2002, 68, 3673-3682.

(28) Parks, D. H.; Beiko, R. G. Identifying biologically relevant differences between metagenomic communities. Bioinformatics 2010, 26 (6), 715-21.

(29) Ulbricht, C. E. Natural Standard Herb \& Supplement Guide: An Evidence-Based Reference; Mosby Elsevier: Missouri, U.S.A., 2010.

(30) Ulbricht, C.; Basch, E. The Authority on Integrative Medicine. Natural Standard. https://naturalmedicines.therapeuticresearch.com.

(31) Duncan, S. H.; Louis, P.; Flint, H. J. Lactate-Utilizing Bacteria, Isolated from Human Feces, That Produce Butyrate as a Major Fermentation Product. Appl. Environ. Microbiol. 2004, 70 (10), 58105817.

(32) Flint, H.; Duncan, S.; Scott, K.; Louis, P. Links between diet, gut microbiota composition and gut metabolism. Proc. Nutr. Soc. 2015, 74 (1), 13-22.

(33) Hugenholtz, J. Citrate metabolism in lactic acid bacteria. FEMS Microbiol. Rev. 1993, 12, 165-178.

(34) Rios-Covián, D.; Ruas-Madiedo, P.; Margolles, A.; Gueimonde, M.; de los Reyes-Gavilán, C. G.; Salazar, N. Intestinal Short Chain Fatty Acids and their Link with Diet and Human Health. Front. Microbiol. 2016, 7, 185.

(35) Weitkunat, K.; Schumann, S.; Petzke, K. J.; Blaut, M.; Loh, G.; Klaus, S. Effects of dietary inulin on bacterial growth, short-chain fatty acid production and hepatic lipid metabolism in gnotobiotic mice. $J$. Nutr. Biochem. 2015, 26, 929-937.

(36) Peshev, D.; Van den Ende, W. Fructans: Prebiotics and immunomodulators. J. Funct. Foods 2014, 8, 348-357.

(37) Lin, H. V.; Frassetto, A.; Kowalik, E. J., Jr.; Nawrocki, A. R.; Lu, M. M.; Kosinski, J. R.; Hubert, J. A.; Szeto, D.; Yao, X.; Forrest, G.; Marsh, D. J. Butyrate and propionate protect against diet-induced obesity and regulate gut hormones via free fatty acid receptor 3independent mechanisms. PLoS One 2012, 7 (4), e35240.

(38) Frost, G.; Sleeth, M. L.; Sahuri-Arisoylu, M.; Lizarbe, B.; Cerdan, S.; Brody, L.; Anastasovska, J.; Ghourab, S.; Hankir, M.; Zhang, S.; Carling, D.; Swann, J. R.; Gibson, G.; Viardot, A.; Morrison, D.; Thomas, E. L.; Bell, J. D. The short-chain fatty acid acetate reduces appetite via a central homeostatic mechanism. Nat. Commun. 2014, 5, 3611.

(39) Zhao, Y.; Wang, J.; Ballevre, O.; Luo, H.; Zhang, W. Antihypertensive effects and mechanisms of chlorogenic acids. Hypertens. Res. 2012, 35 (4), 370-374.

(40) Onakpoya, I. J.; Spencer, E. A.; Thompson, M. J.; Heneghan, C. $\mathrm{J}$. The effect of chlorogenic acid on blood pressure: a systematic review and meta-analysis of randomized clinical trials. J. Hum. Hypertens. 2015, 29 (2), 77-81.

(41) Tajik, N.; Tajik, M.; Mack, I.; Enck, P. The potential effects of chlorogenic acid, the main phenolic components in coffee, on health: A comprehensive review of the literature. Eur. J. Nutr. 2017, 56 (7), $2215-2244$

(42) Orofino Kreuger, M. R.; Grootjans, S.; Biavatti, M. W.; Vandenabeele, P.; D’Herde, K. Sesquiterpene lactones as drugs with multiple targets in cancer treatment. Focus on parthenolide. AntiCancer Drugs 2012, 23, 883-896.

(43) Sternini, C.; Anselmi, L.; Rozengurt, E. Enteroendocrine cells: a site of "taste" in gastrointestinal chemosensing. Curr. Opin. Endocrinol., Diabetes Obes. 2008, 15 (1), 73-78.

(44) Domínguez Avila, J. A.; Rodrigo García, J.; González Aguilar, G. A.; de la Rosa, L. A. The Antidiabetic Mechanisms of Polyphenols
Related to Increased Glucagon-Like Peptide-1 (GLP1) and Insulin Signaling. Molecules 2017, 22 (6), E903.

(45) Kim, H. Y.; Kim, K.; Lee, Y. M.; Cho, H. Aster pseudoglehni extract stimulates cholecystokinin and serotonin secretion in vitro and reduces gastric emptying in vivo. J. Funct. Foods 2017, 35, 436-446.

(46) Delzenne, N. M.; Cani, P. D.; Neyrinck, A. M. Modulation of glucagon-like peptide 1 and energy metabolism by inulin and oligofructose: experimental data. J. Nutr. 2007, 137 (11), 2547S2551S.

(47) Lozupone, C. A.; Stombaugh, J. I.; Gordon, J. I.; Jansson, J. K.; Knight, R. Diversity, stability and resilience of the human gut microbiota. Nature 2012, 489 (7415), 220-230.

(48) Turnbaugh, P. J.; Backhed, F.; Fulton, L.; Gordon, J. I. Dietinduced obesity is linked to marked but reversible alterations in the mouse distal gut microbiome. Cell Host Microbe 2008, 3 (4), 213-23.

(49) Wen, L.; Ley, R. E.; Volchkov, P. V.; Stranges, P. B.; Avanesyan, L.; Stonebraker, A. C.; Hu, C.; Wong, F. S.; Szot, G. L.; Bluestone, J. A.; Gordon, J. I.; Chervonsky, A. V. Innate immunity and intestinal microbiota in the development of Type 1 diabetes. Nature 2008, 455 (7216), 1109.

(50) Parnell, J. A.; Reimer, R. A. Prebiotic fiber modulation of the gut microbiota improves risk factors for obesity and the metabolic syndrome. Gut Microbes 2012, 3 (1), 29-34.

(51) Sonnenburg, J. L.; Bäckhed, F. Diet-microbiota interactions as moderators of human metabolism. Nature 2016, 535, 56-64.

(52) Koliada, A.; Syzenko, G.; Moseiko, V.; Budovska, L.; Puchkov, K.; Perederiy, V.; Gavalko, Y.; Dorofeyev, A.; Romanenko, M.; Tkach, S.; Sineok, L.; Lushchak, O.; Vaiserman, A. Association between body mass index and Firmicutes/Bacteroidetes ratio in an adult Ukrainian population. BMC Microbiol. 2017, 17, 120.

(53) Barlow, G. M.; Yu, A.; Mathur, R. Role of the gut microbiome in obesity and diabetes mellitus. Nutr. Clin. Pract. 2015, 30, 787-97.

(54) Kang, D. W.; Park, J. G.; Ilhan, Z. E.; Wallstrom, G.; LaBaer, J.; Adams, J. B.; Krajmalnik-Brown, R. Reduced incidence of prevotella and other fermenters in intestinal microflora of autistic children. PLoS One 2013, 8 (7), e68322.

(55) Brown, C. T.; Davis-Richardson, A. G.; Giongo, A.; Gano, K. A.; Crabb, D. B.; Mukherjee, N.; Casella, G.; Drew, J. C.; Ilonen, J.; Knip, M.; Hyöty, H.; Veijola, R.; Simell, T.; Simell, O.; Neu, J.; Wasserfall, C. H.; Schatz, D.; Atkinson, M. A.; Triplett, E. W. Gut microbiome metagenomics analysis suggests a functional model for the development of autoimmunity for type 1 diabetes. PLoS One 2011, 6 (10), e25792.

(56) Scheperjans, F.; Aho, V.; Pereira, P. A.; Koskinen, K.; Paulin, L.; Pekkonen, E.; Haapaniemi, E.; Kaakkola, S.; Eerola-Rautio, J.; Pohja, M.; Kinnunen, E.; Murros, K.; Auvinen, P. Gut microbiota are related to Parkinson's disease and clinical phenotype. Mov. Disord. 2015, 30 (3), 350-358.

(57) Biddle, A.; Stewart, L.; Blanchard, J.; Leschine, S. Untangling the genetic basis of fibrolytic specialization by Lachnospiraceae and Ruminococcaceae in diverse gut communities. Diversity 2013, 5, 627640.

(58) Banerjee, S.; Sar, A.; Misra, A.; Pal, S.; Chakraborty, A.; Dam, B. Increased productivity in poultry birds by sub-lethal dose of antibiotics is arbitrated by selective enrichment of gut microbiota, particularly short-chain fatty acid producers. Microbiology 2018, 164 (2), 142-153.

(59) Jiao, J.; Wu, J.; Wang, M.; Zhou, C.; Zhong, R.; Tan, Z. Rhubarb Supplementation Promotes Intestinal Mucosal Innate Immune Homeostasis through Modulating Intestinal Epithelial Microbiota in Goat Kids. J. Agric. Food Chem. 2018, 66 (4), 1047-1057.

(60) Shen, Y.; Xu, J.; Li, Z.; Huang, Y.; Yuan, Y.; Wang, J.; Zhang, M.; $\mathrm{Hu}, \mathrm{S}$.; Liang, Y. Analysis of gut microbiota diversity and auxiliary diagnosis as a biomarker in patients with schizophrenia: A crosssectional study. Schizophr. Res. 2018, DOI: 10.1016/ j.schres.2018.01.002.

(61) de Theije, C. G.; Wopereis, H.; Ramadan, M.; van Eijndthoven, T.; Lambert, J.; Knol, J.; Garssen, J.; Kraneveld, A. D.; Oozeer, R Altered gut microbiota and activity in a murine model of autism spectrum disorders. Brain, Behav., Immun. 2014, 37, 197-206. 
(62) Ino, T.; Mori, K.; Tanaka, K.; Suzuki, K.; Harayama, S. Oscillibacter valericigenes gen. nov., sp. nov., a valerate-producing anaerobic bacterium isolated from the alimentary canal of a Japanese corbicula clam. Int. J. Syst. Evol. Microbiol. 2007, 57, 1840-1845. 